\title{
Simplified graphical correlation for determining flow rate in tight gas wells in the Sulige gas field
}

\author{
Xiao Wei ${ }^{1}$, Wu Xiaodong ${ }^{*}$ and Liu Xiaojuan ${ }^{2}$ \\ ${ }^{1}$ Laboratory of Petroleum Engineering, Ministry of Education, China University of Petroleum, Beijing 102249, China \\ ${ }^{2}$ Xi'an Shiyou University, Xi'an, Shaanxi 710065, China
}

\begin{abstract}
The Sulige tight gas reservoir is characterized by low-pressure, low-permeability and lowabundance. During production, gas flow rate and reservoir pressure decrease sharply; and in the shutin period, reservoir pressure builds up slowly. Many conventional methods, such as the indicative curve method, systematic analysis method and numerical simulation, are not applicable to determining an appropriate gas flow rate. Static data and dynamic performance show permeability capacity, $k h$ is the most sensitive factor influencing well productivity, so criteria based on $k h$ were proposed to classify vertical wells. All gas wells were classified into 4 groups. A multi-objective fuzzy optimization method, in which dimensionless gas flow rate, period of stable production, and recovery at the end of the stable production period were selected as optimizing objectives, was established to determine the reasonable range of gas flow rate. In this method, membership functions of above-mentioned optimizing factors and their weights were given. Moreover, to simplify calculation and facilitate field use, a simplified graphical illustration (or correlation) was given for the four classes of wells. Case study illustrates the applicability of the proposed method and graphical correlation, and an increase in cumulative gas production up to $37 \%$ is achieved and the well can produce at a constant flow rate for a long time.
\end{abstract}

Key words: Low-permeability reservoir, sand thickness, fuzzy optimization method, gas flow rate

\section{Introduction}

The Sulige gas field, located in the western part of the Yishaan slope, Ordos Basin, China, is a giant gas fields. The Sulige reservoir is comprised of Upper Palaeozoic clastic sandstone $\left(\mathrm{H}_{8} \mathrm{~S}_{2}\right)$ in the Shanxi Formation. The development block has a total area of $20,000 \mathrm{~km}^{2}$. The gas reservoir is predominantly developed in the $\mathrm{H}_{8} \mathrm{~S}_{2}$ sandstone formation, with a thickness of 15-35 m and at a depth of approximately $2,800 \mathrm{~m}$. And it is embedded between shale and coal layers, with an average permeability of $0.1-4.0 \mathrm{mD}$.

Up to August 31, 2007, 65 wells have been put into production, and $2.8 \times 10^{6} \mathrm{~L}$ of methanol, glycol, and diethylene glycol have been injected into the formation, and a total of $3.684 \times 10^{8} \mathrm{~m}^{3}$ of gas have been recovered. The average water/ gas ratio was $0.466 \mathrm{~m}^{3} / 10^{4} \mathrm{~m}^{3}$, and oil/gas ratio was $0.056 \mathrm{~m}^{3} /$ $10^{4} \mathrm{~m}^{3}$. The maximum individual-well gas flow rate was 3.744 $\times 10^{4} \mathrm{~m}^{3} / \mathrm{d}$, while the average gas flow rate was $1.1 \times 10^{4} \mathrm{~m}^{3} / \mathrm{d}$.

The Sulige gas reservoir is characterized by low-pressure, low-permeability and low-abundance. The complicated geological conditions present a number of challenges in successful development of this reservoir.

1) The reservoir in $\mathrm{H}_{8} \mathrm{~S}_{2}$ in the Sulige gas field is a typical braided river sedimentary system and effective sands overlap irregularly. Moreover, sand continuity and pay sand

* Corresponding author. mail: wuxd308@263.net

Received October 24, 2007 connectivity are poor (Wang et al, 2002a).

2) Production tests show that gas flow rate was low (below $1.4 \times 10^{4} \mathrm{~m}^{3} / \mathrm{d}$ in average) and the reservoir pressure drops sharply, even at a decline rate of $0.2 \mathrm{MPa} / \mathrm{d}$. In the shut-in period, reservoir pressure builds up slowly. This demonstrates that gas supply is insufficient ( $\mathrm{Li}$ et al, 2006b).

3) Laboratory experiments show that the sands are stresssensitive (Zhang et al, 2007).

4) After a period of production, intermittent production had to be adopted in some wells due to low reservoir pressure.

For such a low-permeability reservoir, a suitable well scheduling is of great importance to obtain a relatively high ultimate gas recovery.

\section{Determination of appropriate flow rate for tight gas wells}

\subsection{Conventional methods}

Because fluid flow in the extremely low-permeability Sulige gas reservoir is complicated, indicative curve method, systematic analysis method and numerical simulation are invalid in determining the initial gas flow rate (Wang et al, 2002b; Wu et al, 2007; Zhu et al, 2007).

1) Indicative curve method

Indicative curve was applied to one typical well drilled in the Sulige reservoir, and the so-called allocated initial gas flow rate determined by this method was $20 \times 10^{4} \mathrm{~m}^{3} / \mathrm{d}$. 
However, field practice shows that the appropriate gas flow rate should be $1.5 \times 10^{4} \mathrm{~m}^{3} / \mathrm{d}$. This indicates that this method was not suitable for determining the initial flow rate of gas well in the Sulige reservoir.

2) Systematic analysis method

The initial gas flow rate of a well, obtained by using the systematic analysis method, were $21 \times 10^{4}$ and $17 \times 10^{4} \mathrm{~m}^{3} / \mathrm{d}$ at wellhead pressures of 4 and $10 \mathrm{MPa}$, respectively (as shown in Fig. 1). The method was not suitable for this reservoir. In Fig. 1, green curves are outflow curves of gas at wellhead pressures of 4 and $12 \mathrm{MPa}$, respectively.

3) Numerical simulation

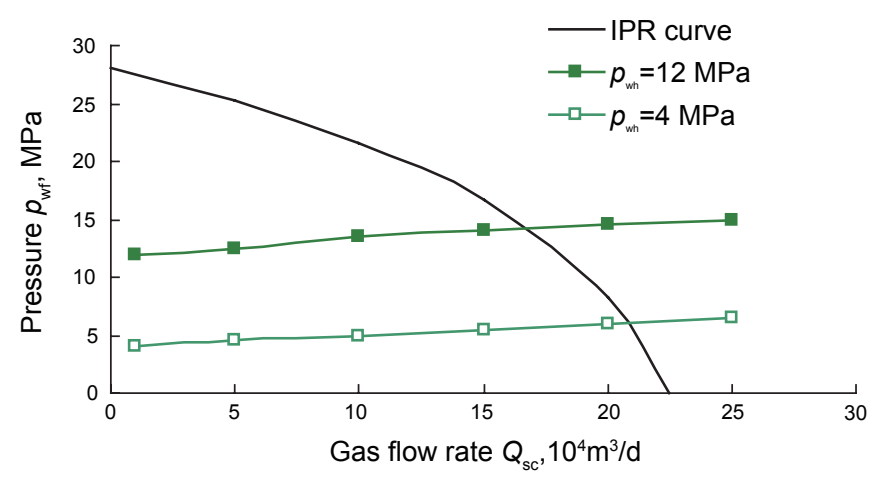

Fig. 1 Result of systematic analysis method used in a typical well in the Sulige gas field

( $p_{\mathrm{wf}}$ is bottom hole flowing pressure and $p_{\mathrm{wh}}$ is well head pressure; IPR is the abbreviation of inflow performance relationship)

Numerical simulation could not be used to predict initial gas flow rate because understanding of fluid flow in extremely-low permeability gas reservoirs is seriously lacking, and a large number of parameters and history matching data required are usually not available. Thus it is difficult to apply numerical simulation to such a new lowpermeability reservoir.

\subsection{Multi-objective fuzzy optimization method}

Field data, as shown in Table 1, indicate that even at the same gas flow rate, pressure decline rates in different wells varied from 0.008 to $0.16 \mathrm{MPa} / \mathrm{d}$ in the first 5 months. Downhole chokes were set almost in every well drilled in the Sulige gas field to prevent gas hydrate formation, which can block tubes. So tubing pressure cannot reflect the real change of reservoir pressure, and casing pressure was recorded and used to analyze the variation of reservoir pressure (Ding et al, 2006; Tang et al, 2006; Wu et al, 2007).

Production-rate history indicates that the wells producing at the same volumetric rate had very distinct casing pressure decline rates. Also, similar gas wells producing at different volumetric rates performed diversely. Intermittent pumping had to be introduced when casing pressure dropped below a given value. Consequently, it is very important for the wells to be correctly classified and to produce at an appropriate flow rate (Li et al, 2006a; Song and Zheng, 2006).

\subsubsection{Formation characteristics}

Laboratory experiments on rock samples from the Sulige reservoir show that with the decline in pore pressure and increase in actual stress, effective permeability dropped sharply at the early stage; when the effective stress increased to approximately $15 \mathrm{MPa}$, effective permeability leveled off, as shown in Fig. 2.

The Sulige reservoir is stress-sensitive, if the existing effective stress increases due to production and then reaches

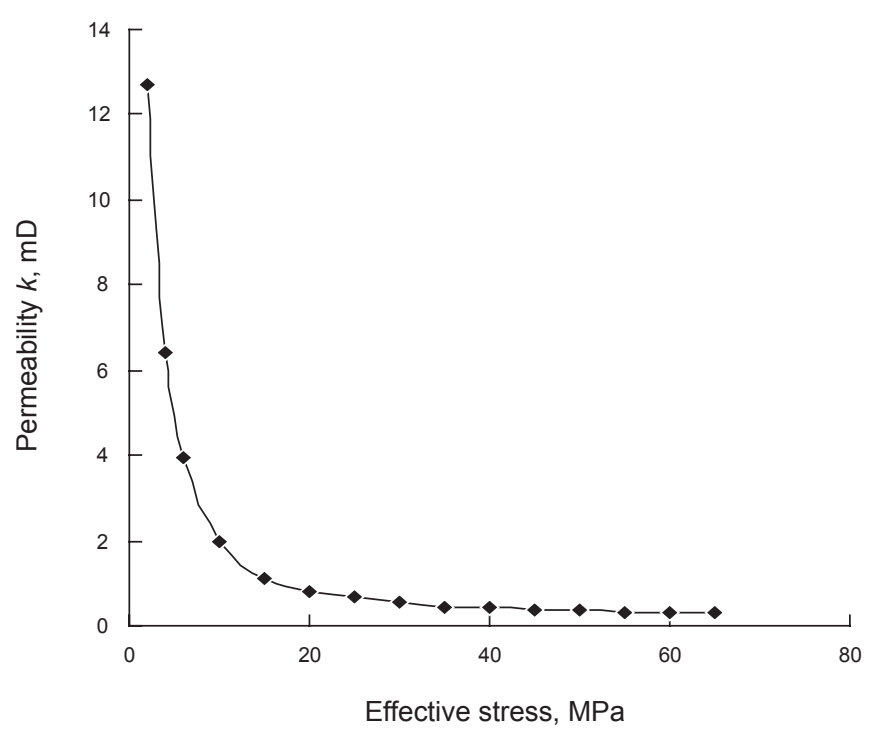

Fig. 2 Relationship between permeability and effective stress

the critical effective stress, plastic deformation of reservoir rock will occur upon further increase in effective stress, as shown in Fig. 3. In actual field practice, the pressure difference between reservoir pressure and bottom hole flowing pressure may be $10-20 \mathrm{MPa}$, which could cause a $20-85 \%$ permeability loss (Palacio and Blasingame, 1993). As a result, a low-permeability zone would form in the immediate vicinity of bottom hole, thereby seriously affecting reservoir productivity. In this case, it is important for the Sulige reservoir to maintain producing pressure drop at a low level (generally below $15 \mathrm{MPa}$ ).

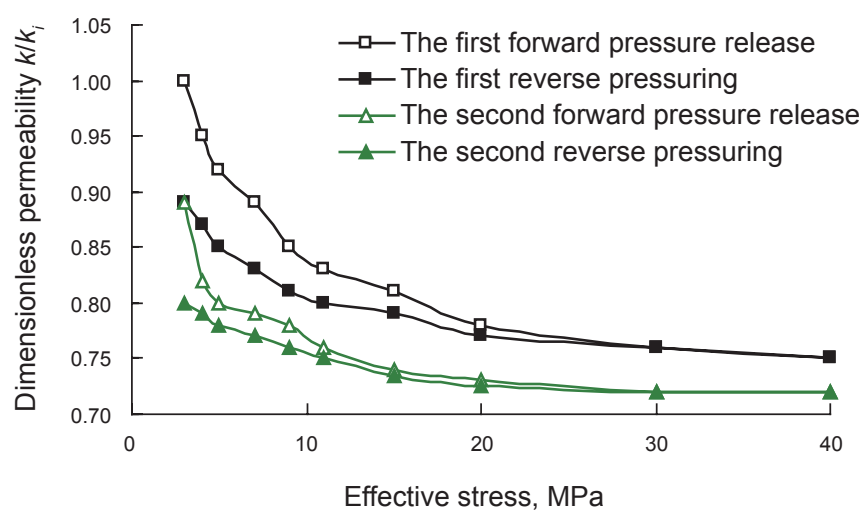

Fig. 3 Relationship between relative permeability and effective stress 
Table 1 Static parameters and production data of low-permeability wells

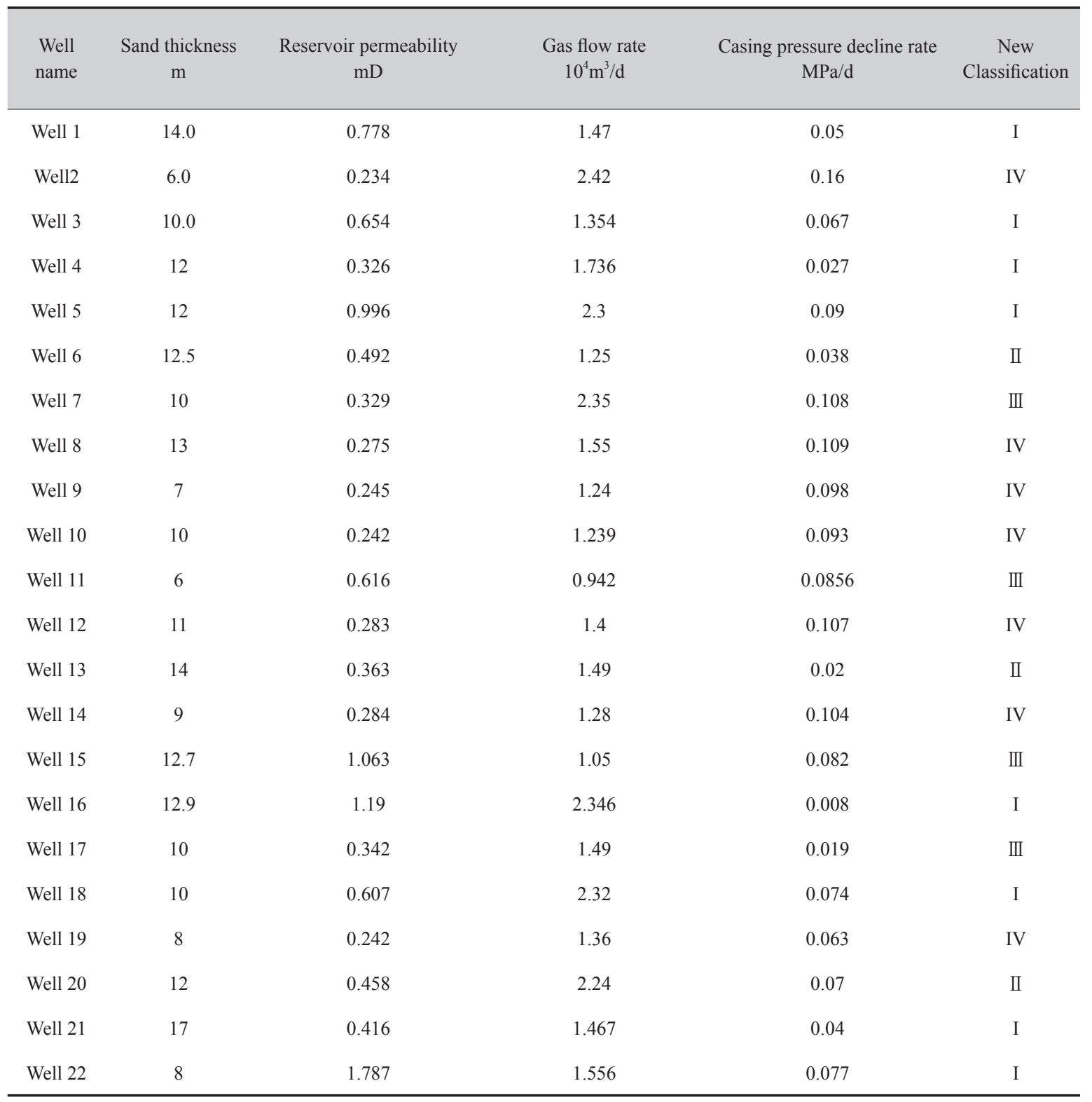

\subsubsection{Well classification}

The influences of most sensitive factors, including reservoir permeability $k$, reservoir thickness $h$, porosity $\phi$, saturation $S_{\mathrm{g}}$, absolute open flow (AOF), on flow potential were studied. Of them, $k$ value reflects the flow capacity of gas in reservoir and $h$ value shows the gas capacity.

Permeability capacity $k$ is the product of effective thickness multiplied by permeability. The deliverability equation (Eq. (1)) for Sulige gas wells shows that permeability capacity, $k h$ is one of key factors influencing gas well productivity. Well test interpretation also indicates a high positive correlation between gas well productivity and permeability capacity.

$$
Q_{\mathrm{sc}}=\frac{774.6 k h\left(p_{\mathrm{e}}^{2}-p_{\mathrm{wf}}^{2}\right)}{T \bar{\mu} \bar{Z}\left(\ln \frac{r_{\mathrm{e}}}{r_{\mathrm{w}}}+S^{\prime}\right)}
$$

where $k$ is reservoir permeability, $\mathrm{mD} ; h$ is effective thickness of the gas-bearing formation, $\mathrm{m} ; p_{\mathrm{e}}$ is reservoir pressure, $\mathrm{MPa} ; p_{\mathrm{wf}}$ is bottom hole flowing pressure, $\mathrm{MPa} ; T$ is reservoir temperature, $K ; \bar{\mu}$ is gas viscosity, $\mathrm{mPa} \cdot \mathrm{s} ; \bar{Z}$ is gas compressibillity factor; $r_{\mathrm{e}}$ is drainage radius, $\mathrm{m} ; r_{\mathrm{w}}$ is wellbore radius, $\mathrm{m} ; S^{\prime}$ is apparent skin factor, dimensionless.

Statistical analyses of formation data, testing parameters and dynamic behavior indicate that an apparent relationship exists between well performance and $k h$. Thus the tight gas wells could be classified into four groups: Class I, II, III and IV. Classification criteria are as follows.

Class I: $k h \geq 6.336$

Class II: $5.49 \leq k h<6.336$

Class III: $3.418 \leq k h<5.49$

Class IV: $k h<3.418$

$k h$ can be expressed as:

$$
k h=\sum k_{i} h_{i}
$$


where $k_{i}$ is the permeability of layer $i, \mathrm{mD} ; h_{\mathrm{i}}$ is the thickness of layer $i, \mathrm{~m}$.

\subsubsection{Determination of reasonable gas flow rate}

Field production analysis shows that semi-empirical curves and graphical correlation are useful and practical without going into details of the complex fluid mechanics in low-permeable porous medium (Agarwal et al, 1998; Litvak et al, 1997).

A multi-objective fuzzy optimization method was selected to determine the gas flow rate of tight gas wells drilled in the Sulige gas field. And dimensionless gas flow rate, period of stable production in months, and recovery at the end of the stable period were selected as optimizing objectives (Gringarten et al, 1974). A comprehensive factor was used as a criterion in determining optimum gas flow rate.

Dimensionless gas flow rate is defined as:

$$
\eta_{V}=\frac{Q_{\mathrm{sc}}}{A O F}
$$

where $Q_{\text {sc }}$ is gas flow rate, $\mathrm{m}^{3} / \mathrm{d}$; and $A O F$ is absolute open flow potential, $\mathrm{m}^{3} / \mathrm{d}$.

Recovery at the end of the stable production period, $\eta_{R}$, is defined as:

$$
\eta_{R}=\frac{G_{\mathrm{p}}}{G_{\mathrm{g}}}
$$

where $G_{\mathrm{p}}$ is the cumulative gas production at the end of the stable production period, $\mathrm{m}^{3}$; and $G_{\mathrm{g}}$ is recoverable reserves, $\mathrm{m}^{3}$.

The comprehensive factor, $f_{\mathrm{ta}}$ is calculated with following equation:

$$
f_{\mathrm{ta}}=\mu\left(\eta_{V}\right) \beta_{V}+\mu\left(\eta_{t}\right) \beta_{t}+\mu\left(\eta_{R}\right) \beta_{R}
$$

where $\mu$ is the membership function; and $\beta$ is the weight.

Membership function of gas production rate, $\mu\left(\eta_{V}\right)$ is:

$$
\mu\left(\eta_{V}\right)= \begin{cases}\exp \left(-\left(\begin{array}{c}
\eta_{V}-0.1 \\
0.42
\end{array}\right)^{2}\right) & \left(0 \leq \eta_{V} \leq 1\right) \\
0 & \left(\eta_{V}<0 \text { or } \eta_{V}>1\right)\end{cases}
$$

Membership function of the period of stable production, $\mu\left(\eta_{t}\right)$ is:

$$
\mu\left(\eta_{t}\right)=\frac{1}{1+5\left(\eta_{t}-5\right)^{0.1}}
$$

Membership function of recovery at the end of the stable production period, $\mu\left(\eta_{R}\right)$ is:

$$
\mu\left(\eta_{R}\right)= \begin{cases}1-\exp \left(17.8826\left(\eta_{R}-0.3\right)^{2}\right) & \left(0.3 \leq \eta_{R}<1\right) \\ 0 & \left(\eta_{R}<0.3\right)\end{cases}
$$

The weights of gas flow rate, period of stable production, and recovery at the end of the stable production period are set as $\beta_{R}=0.3, \beta_{T}=0.3$, and $\beta_{V}=0.4$.

The detailed optimization procedure is described as follows:

1) Calculate the value of $k h$, and determine the class of the well;

2) Set an initial value of casing pressure, $p_{c}$;

3) Set an initial gas flow rate, $Q_{\text {sc }}$;

4) Calculate the bottom hole flowing pressure and reservoir pressure at the initial gas flow rate;

5) Calculate dimensionless gas production rate $\left(\eta_{V}\right)$, period of stable production in months $\left(\eta_{t}\right)$, and recovery at the end of the stable production period $\left(\eta_{R}\right)$;

6) Calculate comprehensive factor, $f_{\mathrm{ta}}$;

7) If the comprehensive factor is maximum, the initial set gas flow rate is appropriate; otherwise, go to Step 3) until obtain the maximum comprehensive factor;

8) Reset an initial value of casing pressure, and repeat step 3) to step 7)

9) A set of data $\left(Q_{\mathrm{sc}}, p_{\mathrm{c}}\right)$ are obtained for a gas well of permeability capacity of $k h$.

\subsubsection{Simplified graphical correlation}

Several sets of data $\left(Q_{\mathrm{sc}}, p_{\mathrm{c}}\right)$ corresponding four classes of gas wells were plotted on the same graph, where abscissa is gas flow rate, ordinate is casing pressure, as shown in Fig. 4. When a vertical well has been drilled, the permeability capacity $k h$ should be first calculated by using reservoir parameters available, according to the corresponding curve shown in Fig. 4, the allocated range of gas flow rate is obtained.

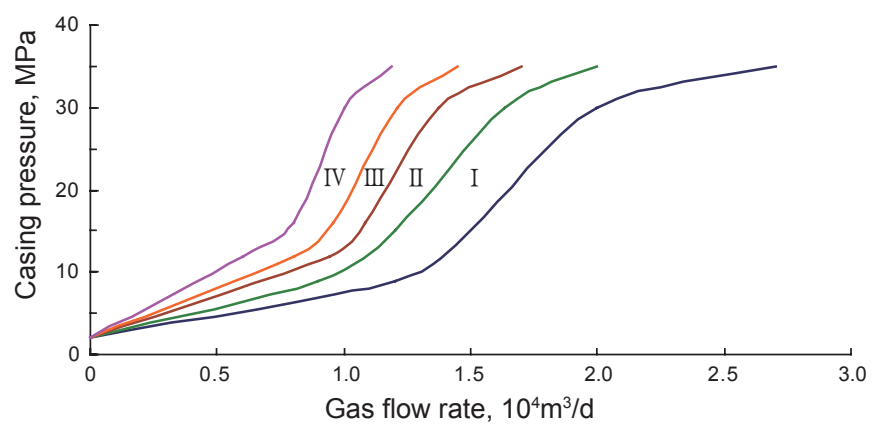

Fig. 4 Graphical correlation for four classes of gas wells

\section{Application}

At present, theoretical method is not suitable to determine the appropriate gas flow rate for tight wells drilled in the Sulige gas field. This paper gives a semi-empirical method based on production data analyses.

However, because the number of production wells is limited, the accuracy of gas flow rate determined by the multi-objective fuzzy optimization method is not so high. With more wells being put into production and more data becoming available, the reliability of the method proposed in this paper will become higher. 
Take Well $\mathrm{Su}$ 14-15-36 as an example. It is a production well located in Block 14, Sulige gas field. The sand is $13 \mathrm{~m}$ thick in this well and reservoir permeability is $0.275 \mathrm{mD}$. The gas flow rate was originally allocated as $1.55 \times 10^{4} \mathrm{~m}^{3} / \mathrm{d}$. As a result, casing pressure decline rate was as high as $0.109 \mathrm{MPa} /$ d. After 130 days of production, casing pressure decreased to $11 \mathrm{MPa}$. Gas flow rate of the well reduced to $0.8-0.9 \times 10^{4} \mathrm{~m}^{3} / \mathrm{d}$ and tended to fall-off further, as shown in Fig. 5. Cumulative gas production from the well was $196 \times 10^{4} \mathrm{~m}^{3}$.

The initial casing pressure of Well Su $14-15-36$ is 26.5
$\mathrm{MPa}$ and the well was classified as Class III according to the product of sand thickness multiplied by reservoir permeability. The optimized gas flow rate is $1.35 \times 10^{4} \mathrm{~m}^{3} / \mathrm{d}$ from Fig. 4. After 130 days of production, casing pressure would be $16.5 \mathrm{MPa}$ and casing pressure decline rate would be only $0.077 \mathrm{MPa} / \mathrm{d}$. In this case, the well could produce at a constant flow rate of $1.06 \times 10^{4} \mathrm{~m}^{3} / \mathrm{d}$. Cumulative gas production of the well could be $270 \times 10^{4} \mathrm{~m}^{3}, 37.8 \%$ more than the actual cumulative production recorded, as shown in Fig. 5.

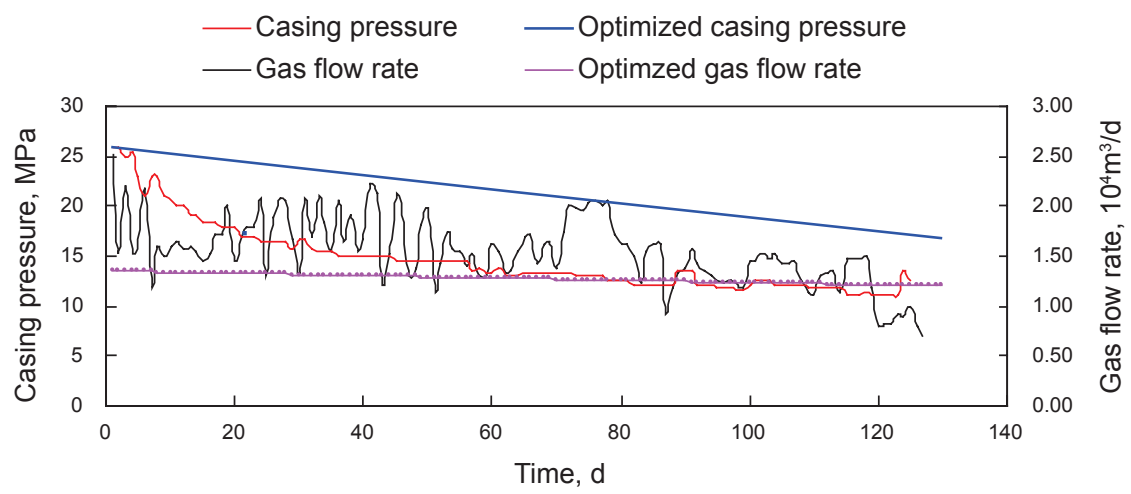

Fig. 5 Production performance of Well Su 14-15-36

\section{Conclusions}

1) Conventional methods are not suitable for determining reasonable gas flow rate of wells drilled in the Sulige tight gas field.

2) Tight gas wells were classified into four classes according to the product of sand thickness multiplied by reservoir permeability, and gas flow rate could be determined based on the multi-objective fuzzy optimization method.

3) A simplified graphical correlation based on the multiobjectives fuzzy optimization method was developed and was successfully applied to determining optimum flow rate of gas wells in the Sulige gas field.

\section{Acknowledgements}

This work was financially supported by National Natural Science Foundation of China (NO. Z02047) and CNPC Program (NO. Z03014). The authors would like to thank them for their approval to publish this paper.

\section{References}

Agarwal R G, Gardner D C, Kleinsteiber S W, et al. Analyzing well production data using combined-type-curve and decline-curve analysis concepts. SPE Annual Technical Conference and Exhibition held in New Orleans, Louisiana, 27-30 September 1998 (SPE paper 49222)

Ding H, Li X H and Wang Z. The downhole throttle technology test study of Sulige Oilfield. Petrochemical Application. 2006. (3): 13-17 (in Chinese)

Gringarten A C, Ramey H J and Raghavan R. Unsteady-state pressure distributions created by a well with a single infinite-conductivity vertical fracture. Society of Petroleum Engineers Journal. 1974. 14(4): $347-360$

Li M T, Yao S L and Shan W W. Laboratory research into stress sensitivity of low-permeability gas reservoirs. Petroleum Geology \& Oilfield Development in Daqing. 2006a. 25(6): 69-72 (in Chinese)

Li R Y, Li Z F, He S L, et al. Sensitivity analysis on parameters affecting gas well productivity. Petroleum Geology \& Oilfield Development in Daqing. 2006b. 25(2): 34-36 (in Chinese)

Litvak M L, Clark A J, Fairchild J W, et al. Integration of Prudhoe Bay surface pipeline network and full field reservoir models. SPE Annual Technical Conference and Exhibition held in San Antonio, Texas, 5-8 October 1997 (SPE paper 38885)

Palacio J C and Blasingame T A. Decline-curve analysis with type curves: Analysis of gas well production data. SPE Rocky Mountain Regional/Low Permeability Reservoirs Symposium held in Denver, Colorado, 12-14 April 1993 (SPE paper 25909)

Song $\mathrm{C} \mathrm{Z}$ and Zheng R C. Stress sensitivity of low-permeability tight gas reservoir and its effect on single well productivity. Petroleum Geology \& Oilfield Development in Daqing. 2006. 25(6): 47-49 (in Chinese)

Tang J W, Jia A L, He D B, et al. Development technologies for the Sulige gas field with low permeability and strong heterogeneity. Petroleum Exploration and Development. 2006. 33(1): 107-110 (in Chinese)

Wang D X, Wang C L, Han X G, et al. Setting-up permeability model for the layered low-permeability reservoir in Changqing Gas Field. Natural Gas Industry. 2002a. 22(6): 78-79 (in Chinese)

Wang S J, Liu J Y and Hao Y H. New equations for determination of non-resistance flow in gas wells. Xinjiang Petroleum Geology. 2002b. 23(5): 427-428 (in Chinese)

Wu X D, Xiao W, Liu X J, et al. Optimizing production system in Sulige Gas Field. Natural Gas Industry. 2007. 27(12): 108-111 (in Chinese)

Zhang L, Zhang M L, Mei H Y, et al. Stress sensibility analysis of lowpermeability gas reservoir and its influence on exploitation. Special Oil and Gas Reservoirs. 2007. 14(3): 55-58 (in Chinese)

Zhu S P, Li W H and Lao Y C. Influence factors of open flow potential in condensate gas well. Special Oil and Gas Reservoirs. 2007. 14(1): 84-86 (in Chinese)

(Edited by Sun Yanhua) 